\title{
Understanding the differential impacts of COVID-19 among hospitalised patients in South Africa for equitable response
}

\author{
N Phaswana-Mafuya, ${ }^{1}$ MSc (Epi), PhD; O Shisana, ${ }^{2,3}$ M Clin Psychol, ScD; W Jassat, ${ }^{4}$ MBBS, MPH; S D Baral, ${ }^{5}$ MD, MPH; \\ ${ }^{1}$ Department of Environmental Health, Faculty of Health Sciences, University of Johannesburg, South Africa \\ ${ }^{2}$ Evidence Based Solutions, Cape Town, South Africa \\ ${ }^{3}$ Department of Psychiatry and Mental Health, Faculty of Health Sciences, University of Cape Town, South Africa \\ ${ }^{4}$ National Institute for Communicable Diseases, Johannesburg, South Africa \\ ${ }^{5}$ Johns Hopkins Bloomberg School of Public Health, Baltimore, Md., USA \\ ${ }^{6}$ Department of Social and Behavioral Sciences, Harvard T H Chan School of Public Health, Boston, Mass., USA \\ ${ }^{7}$ Human and Social Capabilities Research Division, Human Sciences Research Council, Pretoria, South Africa \\ ${ }^{8}$ School of Public Health, Faculty of Health Sciences, University of the Witwatersrand, Johannesburg, South Africa \\ ${ }^{9}$ Department of Psychology, School of Medicine, Faculty of Health Sciences, University of Pretoria, South Africa
} K Makofane, ${ }^{6} \mathrm{MPH}, \mathrm{PhD}$; E Phalane, ${ }^{1} \mathrm{MHSc}, \mathrm{PhD}$; K Zuma, ${ }^{7,8} \mathrm{MSc}$ (Statistics), PhD; N Zungu, ${ }^{7,9} \mathrm{MA}$ (Res Psychol), DPhil; M Chadyiwa, ${ }^{1}$ MBA

Corresponding author: N Phaswana-Mafuya (refilwep@uj.ac.za)

Background. There are limited in-depth analyses of COVID-19 differential impacts, especially in resource-limited settings such as South Africa (SA).

Objectives. To explore context-specific sociodemographic heterogeneities in order to understand the differential impacts of COVID- 19.

Methods. Descriptive epidemiological COVID-19 hospitalisation and mortality data were drawn from daily hospital surveillance data, National Institute for Communicable Diseases (NICD) update reports (6 March 2020 - 24 January 2021) and the Eastern Cape Daily Epidemiological Report (as of 24 March 2021). We examined hospitalisations and mortality by sociodemographics (age using 10-year age bands, sex and race) using absolute numbers, proportions and ratios. The data are presented using tables received from the NICD, and charts were created to show trends and patterns. Mortality rates (per 100000 population) were calculated using population estimates as a denominator for standardisation. Associations were determined through relative risks (RRs), $95 \%$ confidence intervals (CIs) and $p$-values $<0.001$.

Results. Black African females had a significantly higher rate of hospitalisation (8.7\% (95\% CI 8.5 - 8.9)) compared with coloureds, Indians and whites (6.7\% (95\% CI 6.0 - 7.4), 6.3\% (95\% CI 5.5 - 7.2) and 4\% (95\% CI 3.5 - 4.5), respectively). Similarly, black African females had the highest hospitalisation rates at a younger age category of $30-39$ years (16.1\%) compared with other race groups. Whites were hospitalised at older ages than other races, with a median age of 63 years. Black Africans were hospitalised at younger ages than other race groups, with a median age of 52 years. Whites were significantly more likely to die at older ages compared with black Africans (RR 1.07; 95\% CI 1.06 - 1.08) or coloureds (RR 1.44; 95\% CI 1.33 - 1.54); a similar pattern was found between Indians and whites (RR 1.59; 95\% CI 1.47 - 1.73). Women died at older ages than men, although they were admitted to hospital at younger ages. Among black Africans and coloureds, females (50.9 deaths per 100000 and 37 per 100 000, respectively) had a higher COVID-19 death rate than males (41.2 per 100000 and 41.5 per 100000 , respectively). However, among Indians and whites, males had higher rates of deaths than females. The ratio of deaths to hospitalisations by race and gender increased with increasing age. In each age group, this ratio was highest among black Africans and lowest among whites.

Conclusions. The study revealed the heterogeneous nature of COVID-19 impacts in SA. Existing socioeconomic inequalities appear to shape COVID-19 impacts, with a disproportionate effect on black Africans and marginalised and low socioeconomic groups. These differential impacts call for considered attention to mitigating the health disparities among black Africans.

S Afr Med J 2021;111(11):1084-1091. https://doi.org/10.7196/SAMJ.2021.v111i11.15812

SARS-CoV-2, which causes COVID-19, was first identified in December 2019 in Wuhan, China, and has been top on the public health agenda given its magnitude and devastating impacts. The disease contributes to high morbidity and mortality globally and in South Africa (SA). As of 5 May 2021, COVID-19 affected 223 countries and territories, with 153738171 cumulative cases and 3217281 deaths. $^{[1]}$ There were 3891117 cases, 110701 deaths and 3467885 recoveries on the African continent. ${ }^{[2]} \mathrm{SA}$ is the hardesthit country on the African continent, with 1586148 cases, 54511 deaths and 1509656 recoveries as of 5 May 2021. ${ }^{[3]}$ As the COVID19 caseload and death toll increase, its impacts worsen, threatening economies and livelihoods and reversing gains made in reducing morbidities and mortalities globally and nationally.
In SA, the rapid increase in SARS-CoV-2 cases in the second wave started between 5 and 12 November 2020 and ended between 19 and 25 February 2021. The pandemic overwhelmed parts of the already over-extended public health system as a result of the growing demand for testing, contact tracing, isolation and quarantine sites, hospital beds, healthcare providers, and supplies such as ventilators, oxygen and personal protective equipment. ${ }^{[4,5]}$ According to a report released by the National Institute for Communicable Diseases (NICD), most COVID-19 admissions were reported from four provinces in SA. ${ }^{[6]}$ Gauteng ( $n=60$ 397; $27.0 \%$ ) had the highest number of admissions, followed by Western Cape ( $n=45$ 812; 20.5\%), KwaZulu-Natal $(n=43690 ; 19.5 \%)$ and Eastern Cape (EC) $(n=29599 ; 13.2 \%) .{ }^{[6]}$ EC has experienced 
massive challenges in securing hospital beds. ${ }^{[7]}$ In one instance, the private sector hospitals could not accommodate additional patients and referred patients to public hospitals. ${ }^{[8,9]}$ Mortuaries were also overwhelmed and could not cope with burials. ${ }^{[10,11]}$ The pandemic has resulted in overstretched public funds, ${ }^{[12]}$ economic disruption coupled with high rates of unemployment, ${ }^{[13]}$ increased public discord on the best strategy to manage the pandemic, ${ }^{[14]}$ and declining population mental health. ${ }^{[15,16]}$ The SA government responses included a range of COVID-19 impact mitigation strategies such as social welfare support, social relief grants, public-private hospital partnerships, and job creation initiatives for vulnerable populations. ${ }^{[17,18]}$ While these interventions brought temporary relief, they remain unsustainable.

SA is characterised by heterogeneities in socioeconomic status, exposure risk, poverty levels, and healthcare and healthcare access, among others. ${ }^{[1,20]}$ These heterogeneities may result in differential impacts of COVID-19 across groups. Differential impacts of COVID19 have been reported elsewhere. ${ }^{[21-23]}$

Sociodemographic factors may increase the risk of COVID19 diagnoses and deaths in black African communities. ${ }^{[24]}$ There are limited in-depth analyses of COVID-19 differential impacts, especially in resource-limited settings such as SA. ${ }^{[25]}$ It is critical to understand the differential impacts of COVID-19 severity and mortality to guide control measures, inform epidemiological models, ensure appropriate resource allocation, and ultimately attain an equitable response.

\section{Objectives}

To explore available information to strengthen the evidence base for context-specific heterogeneities in sociodemographics that may potentiate or reduce COVID-19 adverse outcomes.

\section{Methods}

This descriptive epidemiological study utilised data from the NICD Surveillance Update Reports, the Daily Hospital Surveillance (DATCOV) report and the Eastern Cape Daily Epidemiological Report (EC Report) for SARS-CoV-2. ${ }^{[6,26]}$ We abstracted cumulative COVID19 cases, recoveries and mortalities as well as sociodemographic characteristics (e.g. age, gender, race, type of facility) reported between 6 March 2020 and 24 January 2021 from DATCOV ${ }^{[6]}$ and as of 24 March 2021 from the EC Report ${ }^{[26]}$ we could not obtain data for exact periods, but observed the epidemiological trends, in which there have not been any huge differences.

To assess differential impacts of COVID-19, we examined hospitalisations and mortality by sociodemographics such as age, sex and race using absolute numbers, proportions, ratios and rates per 100000 people. In addition, for COVID-19 hospitalisation we requested descriptive epidemiological data from the NICD using 215028 COVID-19 hospitalisations reported from 644 healthcare facilities, 393 in the public and 251 in the private sector, between 6 March 2020 and 24 January 2021. The data provided by the NICD were presented in the form of tables and stratified as follows using absolute numbers and proportions: COVID-19 hospitalisations by age, sex and race, and COVID-19 mortality by age, sex, and race. We also assessed descriptive epidemiological data from the EC Report using 31498 COVID-19 hospitalisations reported from eight facilities, 22101 in public and 9397 in private sector facilities, as of 24 March 2021.

Data were reported in 10-year age bands. We assumed that actual ages were uniformly distributed within these bands. The race comparisons are based on the data for people whose race was known.
We constructed charts for each table that the NICD initially provided to assess trends and patterns of hospitalisations and deaths according to sociodemographics in a simple manner.

The data from the NICD DATCOV report that we utilised were based on available information at the time of reporting. There might therefore be slight changes if new information from the laboratory or districts was submitted late. ${ }^{[6]}$

Using the cross-tabulations from NICD descriptive data, we manually computed relative risk (RR), 95\% confidence intervals (CIs) and $p$-values $<0.001$ for hospitalisations and mortality.

Mortality rates were calculated using population estimates as a denominator for each race and age group for standardisation. 'COVID-19 death is defined for surveillance purposes as a death resulting from a clinically compatible illness in a probable or confirmed COVID-19 case; unless there is a clear alternative cause of death that cannot be related to COVID-19; there should be no period of complete recovery between the illness and death. ${ }^{\text {[27] }}$

The case fatality rate (CFR) used was taken from the NICD Epidemiological Report and the EC Report. It was calculated as COVID-19 deaths divided by COVID-19 deaths plus COVID-19 discharges, excluding individuals still in hospital. ${ }^{[6,26]}$

The DATCOV is a hospital-based surveillance system that the SA government endorsed on 15 July 2020. This surveillance system monitors COVID-19 hospital admissions, related health outcomes, and the epidemiology of COVID-19 among hospitalised patients to guide control measures and resource allocation. ${ }^{[6]}$ To date, all 644 SA hospitals (251 private and 393 public hospitals) report COVID-19 hospitalisations to DATCOV. The surveillance system consolidates records received from hospitals on age, sex, race, occupation, comorbid conditions, and outcomes of hospital admission among confirmed SARS-CoV-2 cases (positive reverse transcriptionpolymerase chain reaction assay and antigen tests) who stay in hospital for 1 full day or longer. ${ }^{[6,26]}$

The NICD conducts quality checks on merged data by removing duplicate entries, adding missing data extracted from other sources, and removing patients found to be COVID-19-negative compared with the laboratory master list of all COVID-19 cases. ${ }^{[6,26]}$ Furthermore, the NICD conducts validation checks to identify data errors, and routine checks for correctness, completeness and outliers; they then address these to ensure data quality. The DATCOV surveillance system is further enriched through the Notifiable Medical Conditions (NMC) database and the Master Line List (NMC-SS). Daily patient line lists and summary reports are produced from DATCOV and shared with respective provinces. The NICD has also created application programming interfaces to ensure direct access to the database by key stakeholders who need them for public health interventions. ${ }^{[6]}$ The Ministerial Advisory Committee and the Inter-Ministerial Task Team use the data to inform modelling and guidelines on clinical and public health measures.

The DATCOV surveillance system received approval from the Human Research Ethics Committee (Medical), University of the Witwatersrand (ref. no. M160667). All personal information concerning patients and their health status, treatment, or stay in a health establishment is kept confidential on a secure server and de-linked to ensure anonymity. Similarly, NICD reports contain aggregated patient information without personal identifiers. The names of hospitals are also anonymised when reporting the findings. All data stored in DATCOV are only shared with individuals involved in the surveillance system with password encryption. The NICD surveillance update reports, which are publicly available, were used to determine cumulative cases, deaths and recoveries. 


\section{Results}

COVID-19 hospital admissions by race and sex in SA, 6 March 2020 - 24 January 2021

Based on the DATCOV database with all the hospital admissions for COVID-19 from 6 March 2020 to 24 January 2021, the cumulative data in Table 1 show the distribution in admission (percentages) by race, age and gender. The 215028 persons represent a national hospitalisation rate of 36 per 10000 during this period. The highest hospitalisation rate was among persons aged 50 - 59 years and the lowest among those aged 0 - 9 years. Complete analysis of admissions data by race is hampered by the large number of hospitalised patients whose race was not reported $(n=74854)$. Overall, white people were hospitalised at older ages than other race groups, with a median age of 63 years (Fig. 1). Black Africans were hospitalised at younger ages than other race groups - the median age was 52 years.
Table 2 and Fig. 2 show the number and proportion of deaths by race and gender. Analysis of mortality patterns was conducted by comparing those aged $<50$ years and those aged $\geq 50$ years. There was a significant association in mortality patterns between age and race; whites were significantly more likely to die at older ages than black Africans (RR 1.07; 95\% CI 1.06 - 1.08). A similar pattern of whites being significantly more likely to die at an older age compared with coloureds was seen (RR 1.44; 95\% CI 1.33 - 1.54; $p<0.001$ ), and also between Indians and whites (RR 1.59; 95\% CI $1.47-1.73$; $p<0.001$ ).

Fig. 3 shows the ratio of deaths to hospitalisations by race and gender, drawn from Tables 1 and 2. Overall, the ratio increased with older age. In each age group, this ratio was highest among black Africans and lowest among whites. This difference was more considerable for the older age groups, and among women compared with men.

Analysis of race, age and sex rates of hospitalisation showed variation. In the age group $20-29$ years, black African females had

\begin{tabular}{|c|c|c|c|c|c|c|c|c|c|c|c|c|c|}
\hline \multirow{2}{*}{$\begin{array}{l}\text { Age group } \\
\text { (years) }\end{array}$} & \multicolumn{2}{|c|}{ Black African } & \multicolumn{2}{|c|}{ Coloured } & \multicolumn{2}{|c|}{ Indian } & \multicolumn{2}{|c|}{ White } & \multicolumn{2}{|c|}{ Other } & \multicolumn{2}{|c|}{ Unknown } & \multirow[b]{2}{*}{ Total } \\
\hline & Female & Male & Female & Male & Female & Male & Female & Male & Female & Male & Female & Male & \\
\hline $0-9$ & 1.5 & 2.7 & 2.2 & 3.3 & 0.9 & 1.0 & 0.7 & 0.7 & 1.7 & 0.4 & 1.4 & 1.8 & 1.8 \\
\hline $10-19$ & 2.6 & 2.3 & 1.7 & 1.5 & 0.8 & 0.8 & 1.1 & 0.7 & 4.2 & 1.2 & 1.5 & 1.2 & 1.9 \\
\hline $20-29$ & 8.7 & 5.6 & 6.7 & 4.6 & 6.3 & 2.9 & 4.0 & 1.8 & 10.0 & 9.5 & 7.2 & 4.0 & 6.3 \\
\hline $30-39$ & 16.1 & 14.3 & 12.9 & 9.9 & 12.0 & 10.5 & 7.7 & 5.2 & 23.3 & 23.6 & 14.3 & 10.8 & 13.6 \\
\hline $40-49$ & 17.3 & 19.9 & 17.0 & 18.7 & 18.5 & 20.8 & 12.0 & 13.0 & 20.0 & 24.0 & 15.8 & 17.8 & 17.5 \\
\hline $50-59$ & 21.9 & 23.2 & 23.6 & 26.7 & 23.8 & 26.3 & 19.1 & 21.7 & 12.5 & 18.6 & 21.0 & 23.9 & 22.5 \\
\hline $60-69$ & 17.4 & 18.9 & 19.5 & 21.3 & 19.4 & 21.1 & 19.1 & 23.1 & 9.2 & 13.2 & 18.5 & 20.4 & 18.9 \\
\hline $70-79$ & 9.8 & 9.5 & 11.3 & 9.9 & 12.5 & 12.9 & 18.5 & 21.5 & 15.8 & 7.0 & 11.7 & 12.7 & 11.3 \\
\hline$\geq 80$ & 4.7 & 3.5 & 5.0 & 3.9 & 5.8 & 3.6 & 17.8 & 12.2 & 3.3 & 2.5 & 6.8 & 5.7 & 5.6 \\
\hline Unknown & 0.1 & 0.1 & 0.1 & 0.1 & 0.1 & 0.1 & 0.1 & 0.0 & 0.0 & 0.0 & 1.8 & 1.6 & 0.6 \\
\hline Total, \% & 100 & 100 & 100 & 100 & 100 & 100 & 100 & 100 & 100 & 100 & 100 & 100 & 99.9 \\
\hline Total, $n$ & 64501 & 43652 & 5394 & 4956 & 3629 & 4780 & 5878 & 6847 & 120 & 242 & 39871 & 34983 & 215028 \\
\hline
\end{tabular}

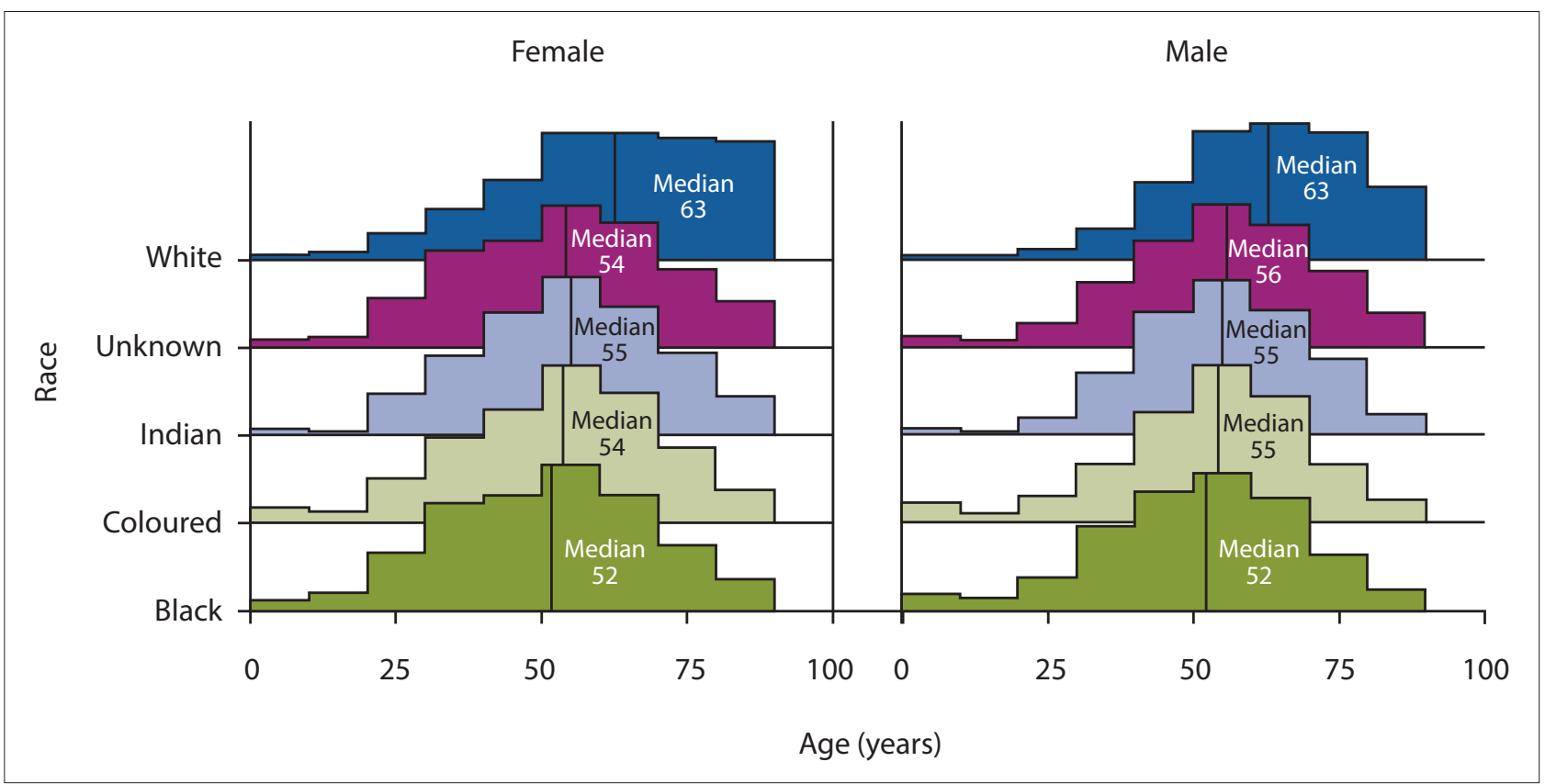

Fig. 1. Age distribution of COVID-19 hospitalisations in South Africa by race and gender, 6 March 2020 - 24 January 2021. Source: National Institute of Communicable Diseases, Daily Hospital Surveillance (DATCOV) data from 6 March 2020 to 24 January 2021 ${ }^{[6]}$ (based on Table 1). 
Table 2. Cumulative number of deaths (n) from COVID-19 by race, sex and age and mortality rates due to COVID-19 in South Africa, 6 March 2020 - 24 January 2021

\begin{tabular}{|c|c|c|c|c|c|c|c|c|c|c|c|}
\hline \multirow[b]{2}{*}{ Age group (years) } & \multicolumn{2}{|c|}{ Black African } & \multicolumn{2}{|c|}{ Coloured } & \multicolumn{2}{|c|}{ Indian } & \multicolumn{2}{|c|}{ White } & \multicolumn{2}{|c|}{ Unknown } & \multirow[b]{2}{*}{ Total } \\
\hline & Female & Male & Female & Male & Female & Male & Female & Male & Female & Male & \\
\hline $0-9$ & 53 & 42 & 0 & 6 & 1 & 1 & 1 & 0 & 8 & 7 & 119 \\
\hline $10-19$ & 41 & 40 & 2 & 3 & 0 & 0 & 4 & 1 & 14 & 13 & 118 \\
\hline $20-29$ & 241 & 136 & 12 & 7 & 10 & 7 & 8 & 4 & 86 & 79 & 590 \\
\hline $30-39$ & 725 & 571 & 47 & 47 & 39 & 36 & 17 & 17 & 324 & 275 & 2098 \\
\hline $40-49$ & 1370 & 1197 & 99 & 128 & 83 & 135 & 60 & 98 & 632 & 751 & 4553 \\
\hline $50-59$ & 2794 & 2209 & 208 & 272 & 129 & 220 & 118 & 211 & 1235 & 1531 & 8927 \\
\hline $60-69$ & 3498 & 2990 & 317 & 330 & 167 & 278 & 200 & 356 & 1718 & 1936 & 11790 \\
\hline $70-79$ & 2464 & 1785 & 194 & 189 & 146 & 220 & 233 & 452 & 1356 & 1604 & 8643 \\
\hline$\geq 80$ & 1361 & 714 & 117 & 76 & 85 & 74 & 291 & 338 & 922 & 828 & 4806 \\
\hline Unknown & 3 & 2 & 0 & 2 & 0 & 1 & 0 & 0 & 107 & 115 & 230 \\
\hline Total & 12550 & 9686 & 996 & 1060 & 660 & 972 & 932 & 1477 & 6402 & 7139 & 41874 \\
\hline Rate/100 000 & 50.9 & 41.2 & 37 & 41.5 & 87.6 & 123.9 & 38.6 & 65.1 & 22 & 23.4 & 70.2 \\
\hline
\end{tabular}

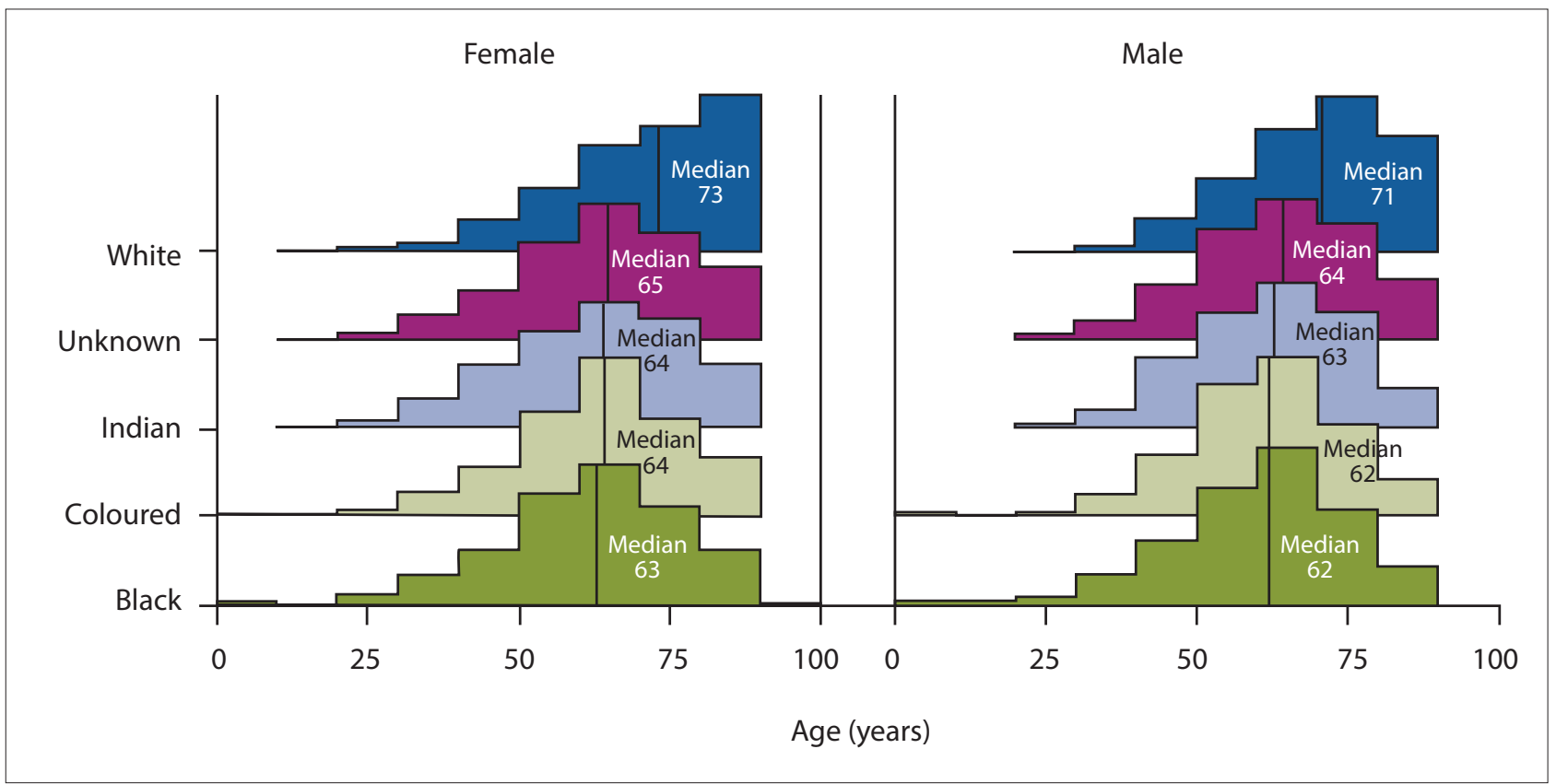

Fig. 2. Age distribution of COVID-19 deaths in South Africa by race and gender, 6 March 2020 - 24 January 2021. Source: National Institute of Communicable Diseases, Daily Hospital Surveillance (DATCOV) data from 6 March 2020 to 24 January 2021. ${ }^{[6]}$

a significantly higher rate of hospitalisation $(8.7 \%$ (95\% CI $8.5-8.9)$ compared with coloureds, Indians and whites $(6.7 \%$ (95\% CI 6.0 7.4), 6.3\% (95\% CI 5.5 - 7.2) and 4\% (95\% CI 3.5 - 4.5), respectively). Similarly, black African females in the age group 30 - 39 years had a higher rate $(16.1 \%)$ compared with other race groups. In 40 49 -year-olds, Indian males had the highest hospitalisation rate at $20.8 \%$ compared with other races, while in the age group $50-59$ years, coloured males had the highest hospitalisation rate $(26.7 \%)$ compared with other races. In the age groups $60-69$ years, white males had the highest hospitalisation rate $(23.1 \%)$ compared with other races, among those aged $70-79$ years, they had the highest rate at $21.5 \%$, and in the $\geq 80$ years group, white females had the highest rate at $17.8 \%$. The hospitalisation rate was highest (22.5\%) among those aged 50 - 59 years (Table 1).

Table 2 shows overall COVID-19-related mortality rates per 100000 by race and sex as well as the number of deaths by race and sex. Males of Indian origin (123.9 deaths per 100 000) had a particularly high death rate due to COVID-19, while coloured females (37 per 100 000) had the lowest death rate. Among black Africans and coloureds, females (50.9 per 100000 and 37 per 100000 , respectively) had a higher death rate than black African and coloured males ( 41.2 per 100000 and 41.5100000 , respectively). The opposite pattern was seen among Indians and whites, where males had higher rates of COVID-19 deaths than females.

\section{EC COVID-19 admissions and outcomes in health} facilities as of 24 March 2021

EC was chosen to demonstrate that the differential impacts observed at national level were also seen at provincial level.

The cumulative number of cases and deaths was 195006 and 11 351, respectively, as of 24 March 2021 (Table 3). There was a recovery rate of $94.1 \%$. There were slight gender differences in deaths; 
Table 3. Cumulative number of tests and positive COVID-19 cases as well as recoveries, deaths, admissions and outcomes in Eastern Cape Province, South Africa, as of 24 March 2021

\begin{tabular}{|c|c|c|c|}
\hline \multicolumn{4}{|c|}{ Cumulative cases, deaths and recoveries } \\
\hline Total confirmed cases, $N$ & \multicolumn{2}{|c|}{ Total deaths, $n$ (CFR) } & Recoveries, $n$ (recovery rate) \\
\hline 195006 & \multicolumn{2}{|c|}{11351 (5.8\%; males 6.3\%, females 5.5\%) } & $183447(94.1 \%)$ \\
\hline Tests, admissions and outcomes & Public, $n$ & Private, $n$ & Total, $n$ \\
\hline Tests & 344020 & 563744 & 907764 \\
\hline Admissions & 22101 & 9397 & 31498 \\
\hline \multicolumn{4}{|l|}{ Outcomes } \\
\hline Died & 2268 & 7143 & 9411 \\
\hline Discharged alive & 7035 & 13314 & 20349 \\
\hline In hospital & 53 & 50 & 103 \\
\hline Transfer to other facility & 34 & 1553 & 1587 \\
\hline ICU & 18 & 2 & 20 \\
\hline High care & 2 & 0 & 2 \\
\hline General & 33 & 48 & 81 \\
\hline On oxygen & 15 & 22 & 37 \\
\hline Ventilated & 6 & 2 & 8 \\
\hline
\end{tabular}

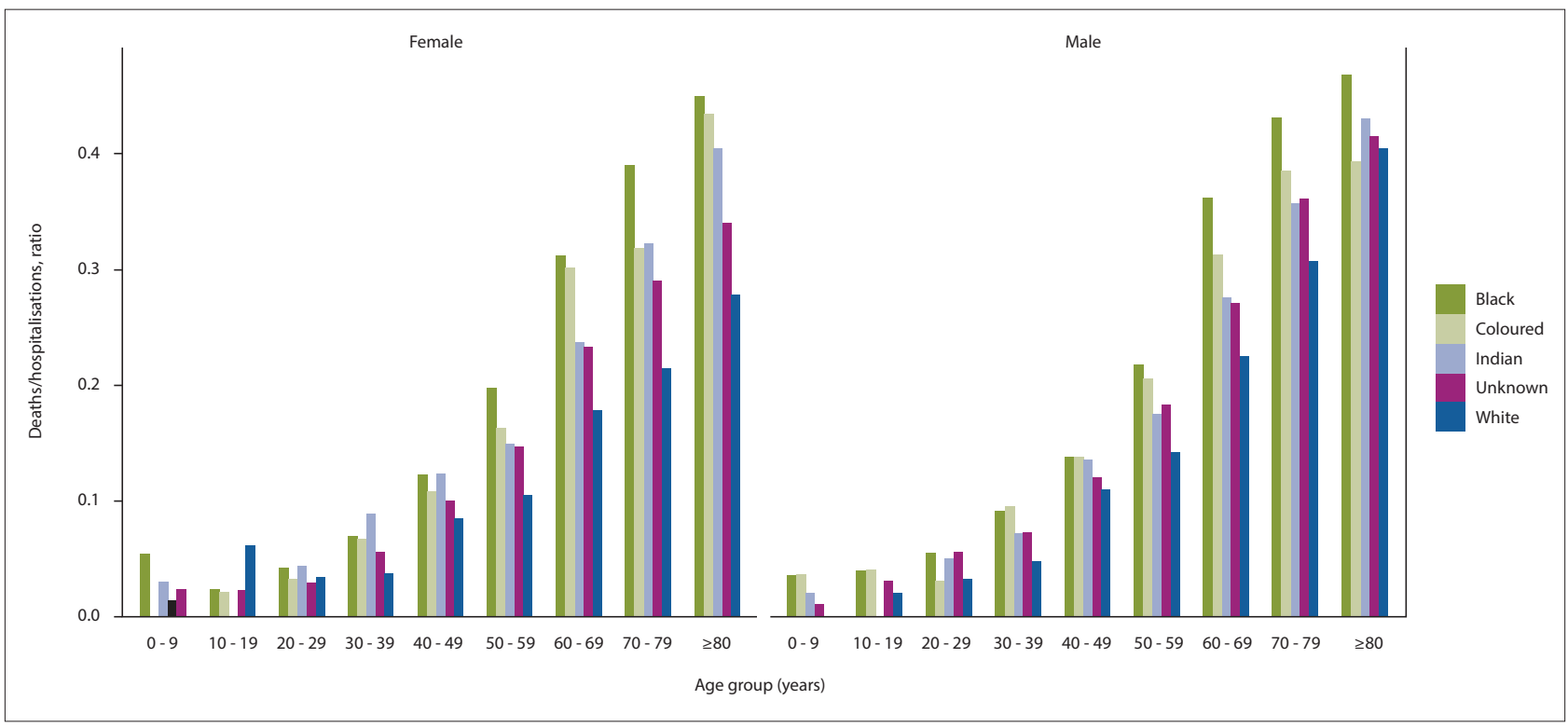

Fig. 3. Ratio of COVID-19 deaths to hospitalisations in South Africa, 6 March 2020 - 24 January 2021. Source: National Institute of Communicable Diseases, Daily Hospital Surveillance (DATCOV) data from 6 March 2020 to 24 January 2021. [6]

of the $5.8 \%$ of patients who died, more males $(6.3 \%)$ than females $(5.5 \%)$ died.

The cumulative number of SARS-CoV-2 hospitalisations was 31 498. The majority of reported hospitalisations ( $n=22101 ; 70.2 \%)$ were in public sector health facilities compared with private sector ones ( $n=9$ 397; 29.8\%). Similarly, more SARS-CoV-2 tests were conducted in public sector health facilities $(n=563744 ; 62.1 \%)$ compared with private sector ones $(n=344020 ; 39.9 \%)$. When stratified by gender, more women than men had SARS-CoV-2 tests (Fig. 4).

At the provincial level, EC had a smaller number of patients discharged alive in the public care sector $(n=7035)$ than in the private sector ( $n=13314$ ) (Table 3 ). Of the $29.9 \%$ of deaths of hospitalised patients due to SARS-CoV-2-related causes, $75.9 \%$ ( $n=7$ 143) occurred in public sector facilities. Of the total number of patients, 20349 (64.6\%) were discharged alive and 103 (0.33\%) were currently admitted. Of those who were currently admitted, 81 (78.6\%) were in general wards, 20 (20.4\%) in intensive care units (ICUs) and 2 (1.9\%) in high care; 37 hospitalised patients (35.9\%) were on oxygen, and 8 (7.8\%) were on ventilation.

The CFR differed by age group and sex (Fig. 5); specifically, it differed between the younger and older populations, with the latter having a higher CFR. The SARS-CoV-2-related CFR increased with advancing age. The CFR also differed by gender, with males having a higher CFR than females.

\section{Discussion}

\section{COVID-19 admissions}

The findings show differential impacts of COVID-19 in admissions and mortality in population and age groups. Admissions and deaths occurred later in age for whites compared with black Africans. 


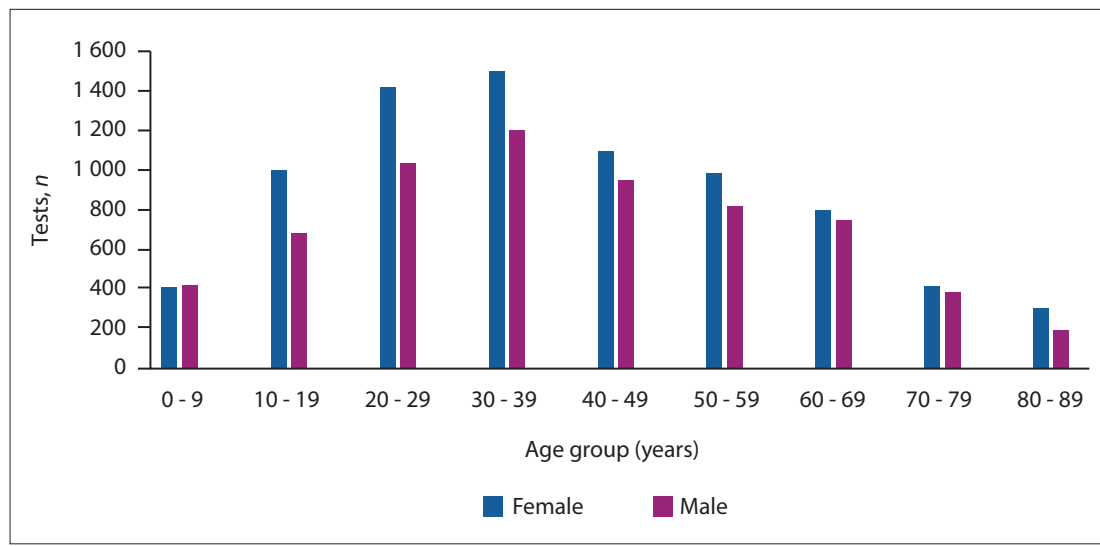

Fig. 4. SARS-CoV-2 tests by age group and gender in the past 31 days, as of 24 March 2021. Source: Eastern Cape Daily Epidemiological Report No. 355 as of 24 March 2021. ${ }^{[26]}$

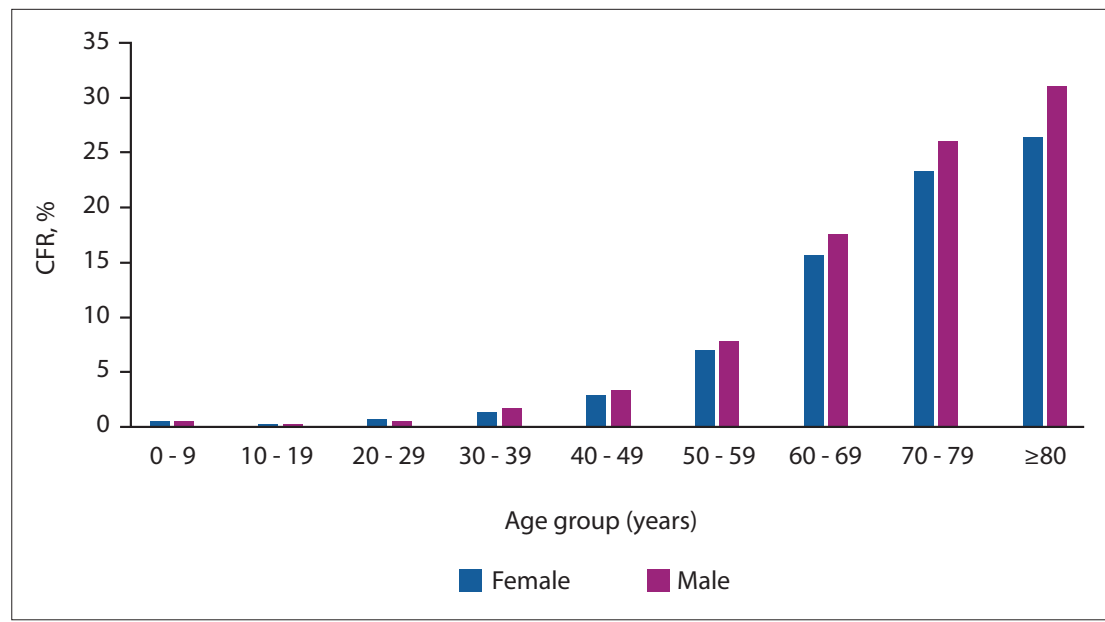

Fig. 5. COVID-19-related CFR in Eastern Cape Province by age group and sex as of 24 March 2021. Source: Eastern Cape Daily Epidemiological Report No. 355 as of 24 March 2021. ${ }^{[26]}$ (CFR $=$ case fatality rate.)

Admission differences may be due to racial disparities in exposure and susceptibility due to disproportionately higher rates of non-communicable diseases and disease severity ${ }^{[27]}$ Differential impacts of SARSCoV-2-related deaths were evident in EC. The vulnerability of black Africans to other pandemics in SA (e.g. tuberculosis (TB) and HIV) is well known, ${ }^{[28]}$ and similar observations were made in the USA, where African Americans had disproportionately high infection and mortality rates due to COVID-19. ${ }^{[25,27,29,30]}$ Considered attention to race and socioeconomic barriers is needed.

Proportions of COVID-19 hospitalisations were highest among persons aged 50 - 59 years $(22.5 \%)$ and lowest among those aged 0 9 years $(1.8 \%)$. The association between older age and hospital admission has been reported previously. ${ }^{[6]}$ Factors that may explain higher admission rates among the elderly include deterioration of health with age, ${ }^{[31]}$ with consequent weakening of immune function (immunosenescence) that hinders pathogen recognition, alert signalling and clearance, ${ }^{[32]}$ and a heightened inflammatory environment (inflammaging) which is caused by an overexcited yet ineffective alert immune system. ${ }^{[32]}$ Consequently, older people with infectious diseases such as COVID-19 have an increased tendency to develop opportunistic infections, ${ }^{[33]}$ which may rapidly develop into severe illnesses. ${ }^{[32]}$ Furthermore, age-related comorbidities are highly prevalent in the ageing population in SA. ${ }^{[34,35]}$ The elderly may also have difficulties in accessing healthcare and in implementing hygiene behaviours. ${ }^{[19]}$ SA has a growing ageing population, with $8.5 \%$ of the population being $>60$ years old. ${ }^{[19]}$ In a study of 2491 adults hospitalised with laboratory-confirmed COVID-19 in the USA, older age and male sex were associated with admission to ICUs. ${ }^{[3]}$ Findings from China and the USA have also shown that older age was one of the determinants of COVID-9 hospitalisation. ${ }^{[37,38]}$ There is a need to address health needs and access in this population.
The SA healthcare system services an estimated population of $>59$ million. It is composed of private and public sectors, with $82 \%$ of the population accessing healthcare from the public health sector, while $17 \%$ use medical aid to access private healthcare. The public health system is overstretched and under-resourced. However, access to private health services depends mainly on the ability to pay ${ }^{[39]}$ Public healthcare is characterised by challenges such as long waiting hours, rushed appointments, old facilities, poor disease control and prevention practices, and poor quality of care compared with private healthcare. ${ }^{[39,40]}$ These differences may be magnified further by COVID-19. Admission to a public sector facility has been associated with an increased risk of COVID19 mortality ${ }^{[6]}$

The present study revealed that higher proportions of black Africans than other racial groups were admitted to public health facilities. Of the majority $(>80 \%)$ of South Africans who use the public healthcare system, most are black, while most of the $<20 \%$ who use private healthcare are white. ${ }^{[41]}$ Approximately $50 \%$ of health resources are enjoyed by $16 \%$ of South Africans (mainly whites) ${ }^{[42]}$ Approximately $73 \%$ of South Africans, mostly black Africans, did not have medical aid in 2018 and therefore cannot afford or access private medical care. ${ }^{[41]}$ Black Africans have limited resources (assets, wealth and medical insurance), which may affect access to good healthcare or delay seeking healthcare. ${ }^{[40,43]}$ Insurance coverage has been shown to be strongly associated with better health outcomes, ${ }^{[4]}$ yet in 2018 , only $10 \%$ of black Africans belonged to medical aid schemes that would afford them access to private healthcare. ${ }^{[45]}$ This inequity implies that COVID-19 worsens existing preventable health differences that remain persistent in SA and increases national levels of poverty and malnutrition. ${ }^{[46,47]}$

Gender differences in rates of COVID19 hospital admissions were also observed. Although women were admitted at younger ages than men, they tended to die at older ages. The reasons for this finding have been alluded to in an earlier section of the discussion.

\section{Mortality}

The results show that COVID-19 in-hospital mortality was highest in black Africans, followed by coloureds, Indians and whites. The differences may be attributed to preexisting inequalities, as black Africans have a disproportionately high burden of unemployment and poverty (such as no 
education, no income, no shelter and no food) than other population groups in SA. ${ }^{[19]}$ These conditions have consistently led to higher mortality among black Africans (68.5\%) compared with whites (9.5\%), coloureds (7.7\%) and Indians (1.8\%). ${ }^{[4]}$ The high mortality of black Africans due to other pandemics in SA, such as TB and HIV, is well known. ${ }^{[19]}$ Similar observations were made in the USA, where African Americans had disproportionately high infection and mortality rates due to COVID-19. ${ }^{[4,50]}$ COVID-19 deaths were also higher among the elderly, as expected. In 2009, 151700 - 575400 deaths among H1N1 admissions were of older patients ( $\geq 50$ years). ${ }^{[51,52]}$

The results of the present study show higher mortality among males than females. Similarly, men (6.3\%) had a higher CFR than women (5.5\%). Men may delay visiting health facilities because they generally have poor health-seeking behaviour, which may increase disease severity. They may also have underlying health conditions of which they are not aware. Men are also known to have more risky health behaviours, such as tobacco and alcohol use, than women. ${ }^{[53]}$ These risky behaviours are associated with an increased risk of cardiovascular disease (CVD), and CVD is reported to be higher in men than women. ${ }^{[54]}$ Several factors may explain the lower mortality in women. Generally, women are known to have better health-seeking behaviours than men ${ }^{[55]}$ which could increase their opportunity to be screened for COVID-19 and diagnosed early and not become severely ill. Specifically, women are traditionally responsible for the family's health and are likely to be knowledgeable about pathological symptoms. As such, they have been reported to be more likely to use healthcare services than men. It is important to note that although the mortality rate was higher for men than women, females' cumulative incidence risk has consistently remained high since the beginning of the pandemic. This risk may be attributed to gender inequalities such as women being in service occupations and vulnerabilities in domestic and local chores; many women are compelled to be part of super-spreader events as they need to cook and serve food at such events for financial security. ${ }^{[56]}$ These findings provide insight into gender-related differences in healthcare or disease risk. Analysis and documentation of these differences are essential for improving service delivery and assessing the dual goals of improving health status and reducing health inequalities.

It should be noted that the in-hospital mortality rate does not represent total COVID-19 mortality, as many deaths occur outside healthcare facilities. For example, in EC, $>40 \%$ of persons who died outside healthcare facilities tested positive for SARS-CoV-2.

\section{Study strengths and limitations}

The present study should be interpreted within the context of its strengths and potential limitations. It contributes to the understanding of COVID-19 impacts in SA, as few studies have highlighted the socioeconomic inequalities that shape COVID-19 impacts. Some patients who were not admitted to hospital may have been admitted to other institutions. Some discharged patients may have been readmitted elsewhere with critical illness or could have died after discharge, resulting in under- and/or overestimating the study's outcomes (hospitalisation and mortality). The period for the data used in this study differed (for DATCOV, we used data from 6 March 2020 to 24 January 2021, and for EC we used data as of 24 March 2021).

\section{Conclusions}

This review revealed the heterogeneous nature of COVID-19 impacts in SA and highlights population groups that are more vulnerable and prone to severe COVID-19 impacts. Existing socioeconomic inequalities seem to shape the effects of COVID-19, both directly and indirectly. COVID-19 may severely impact black Africans, marginalised groups and groups with low socioeconomic status (SES). These differential impacts call for considered attention to mitigating the health disparities among African black populations, including urgent implementation of the comprehensive National Health Insurance, which would expand health resources and investments to under-served communities and fulfil the constitutional right of every SA citizen to health and the National Development Plan key objective, 'Health care for all. ${ }^{[57]}$ These unique impacts are not often spoken about, yet they have major public health implications for the current and subsequent waves of COVID-19. Understanding the differential impacts of the COVID-19 pandemic on health services, health outcomes and equity is critical, not only for the attainment of equity and social justice but also for planning and adapting public health responses, identification and application of risks and evidence-based strategies, and reduction of the burden of disease, and for advocacy purposes. We call for deliberate efforts to collect SES data in the country's surveillance systems to design targeted, focused and feasible interventions.

\section{Declaration. None.}

Acknowledgements. The authors are grateful to the NICD and the EC Department of Health for making the COVID-19 data available.

Author contributions. NP-M led the conceptualisation and writing of all sections of the manuscript. OS co-led the conceptualisation and writing of the different sections of the manuscript. WJ described the methodology and made input on the results. SDB assisted with conceptualisation, review and input on different versions of manuscript. KM did some of the graphics and description of findings. EP reviewed the literature and references, collated inputs and reviewed the manuscript. KZ did computations of $p$-values and relative risks and reviewed the manuscript. NZ made input on the literature and reviewed the manauscript. MC assisted with references, redrawing of graphics and review of the manuscript. All authors reviewed the manuscript.

Funding. Apart from the publication fees paid by the University of Johannesburg, the author(s) received no financial support for the research and authorship.

Conflicts of interest. None.

1. World Health Organization. Coronavirus (COVID-19) dashboard. 2021. https://covid19.who.int/ (accessed 5 May 2021)

2. Centers for Disease Control and Prevention Africa. Coronavirus Disease 2019 (COVID-19). 2021 https://africacdc.org/covid-19/ (accessed 5 May 2021).

3. Department of Health, South Africa. COVID-19 Online Resource \& News Portal. Update on Covid-19 (05th May 2021). 5 May 2021. https://sacoronavirus.co.za/2021/05/05/update-on-covid-19-05thmay-2021/ (accessed 6 October 2021).

4. Mendelson M, Booyens L, Boutall A, et al. The mechanics of setting up a COVID-19 response: Experiences of the COVID-19 epidemic from Groote Schuur Hospital, Cape Town, South Africa. S Afr Experiences of the COVID-19 epidemic from Groote Schuur Hospital, Cape Tow
Med J 2020;110(9):968-972. https://doi.org/10.7196/SAMJ.2020.v1 10i10.15215

Med J 2020;110(9):968-972. https://doi.org/10.7196/SAMJ.2020.v110i10.15215 Burke J. South Africa struggles to contain second Covid wave with new strain. Guardian, 22 December 2020. https://www.theguardian.com/world/2020/dec/22/south-africa-struggles-contain-second-covidwave-new-strain (accessed 23 March 2021)

6. National Institute for Communicable Diseases. COVID-19 hospital surveillance update: South Africa Week 10 2021. 2021. https://www.nicd.ac.za/wp-content/uploads/2021/03/NICD-COVID-19Weekly-Sentinel-Hospital-Surveillnace-update-Week-10-2021.pdf (accessed 6 October 2021).

7. Parliamentary Monitoring Group. Eastern Cape COVID-19 Challenges \& Interventions: Impact of alcohol on health services. 22 July 2020. https://pmg.org.za/page/ EasternCapeCOVID19Challenges\&InterventionsImpactofalcoholonHealthServices (accessed 23 March 2021)

8. News24. Bruising financial losses and near capacity: Covid-19 second wave hits SA's private hospitals. 18 December 2020. https://www.news24.com/fin24/companies/health/bruising-financial-losses-andnear-capacity-covid-19-second-wave-hits-sas-private-hospitals-20201218 (accessed 6 October 2021). Jassat W, Madura C, Ozougwu L, et al. Increased mortality among individuals hospitalised with COVID-19 during the second wave in South Africa. MedRxiv 2021 (epub 10 March 2021). https://doi org/10.1101/2021.03.09.21253184

10. Business Insider SA. SA's Covid-19 dead are supposed to be buried fast but even cremations are taking weeks. 15 January 2021. https://www.businessinsider.co.za/hospitals-are-coping-but-home-affairs-isdelaying-burials-funeral-parlours-say-2021-1 (accessed 23 March 2021). 
11. eNCA. COVID-19 in SA: Eastern Cape funeral parlours struggle to cope. 5 December 2020. https://www. enca.com/news/covid-19-sa-eastern-cape-funeral-parlours-struggle-cope (accessed 23 March 2021).

12. Department of the Treasury, South Africa. Building a bridge to recovery beyond COVID-19. 2020 http://www.treasury.gov.za/documents/National\%20Budget/2020S/2020\%20Supplementary\%20 Budget\%20presentation.pdf (accessed 23 March 2021)

13. The Conversation. South Africa sets aside more money for COVID-19 but lacks a spending strategy. 29 June 2020. https://theconversation.com/south-africa-sets-aside-more-money-for-covid-19-butlacks-a-spending-strategy-141619 (accessed 23 March 2021)

14. The Conversation. South Africa’s COVID-19 strategy needs updating: Here's why and how. 13 May 2020. https://theconversation.com/south-africas-covid-19-strategy-needs-updating-heres-why-andhow-138368 (accessed 23 March 2021)

15. Kim AW, Nyengerai T, Mendenhall E. Evaluating the mental health impacts of the COVID-19 pandemic in urban South Africa: Perceived risk of COVID-19 infection and childhood trauma predict adult depressive symptoms. Psychol Med 2020;1-13. https://doi.org/10.1017/S0033291720003414

16. Human Sciences Research Council. Living through global trauma: Mental-health implications of COVID-19 from a developing country perspective. 16 April 2020. http://www.hsrc.ac.za/en/news/ COVID-19 from a developing country perspective. 16 Ap
general/mental-health-covid-19 (accessed 23 March 2021).

17. The Presidency, South African Government. President Cyril Ramaphosa: Additional coronavirus COVID-19 economic and social relief measures. 21 April 2020. https://www.gov.za/speeches/ president-cyril-ramaphosa-additional-coronavirus-covid-19-economic-and-social-relief\# (accesse 23 March 2021)

18. Department of the Treasury, South Africa. Budget 2021: Budget review. 24 February 2021. http://www. treasury.gov.za/documents/national\%20budget/2021/review/FullBR.pdf (accessed 23 March 2021).

19. Statistics South Africa. Mid-year population estimates 2020. Statistical realease P0302. 9 July 2020. http://www.statssa.gov.za/publications/P0302/P03022020.pdf (accessed 23 March 2021).

20. Statistics South Africa. Results from Wave 2 survey on the impact of the COVID-19 pandemic on employment and income in South Africa. 20 May 2020. http://www.statssa.gov.za/publications/ Report-00-80-03/Report-00-80-03May2020.pdf (accessed 23 March 2021)

21. Balmford B, Annan JA, Hargreaves JC, Altoè M, Batema IJ. Cross-country comparisons of COVID-19: Policy, politics and the price of life. Environ Resource Econ 2020;76(4):525-551. https://doi. org/10.1007/s10640-020-00466-5

22. Lone SA, Ahmad A. COVID-19 pandemic - an African perspective. Emerg Microbes Infect 2020;9(1):1300-1308. https://doi.org/10.1080/22221751.2020.1775132

3. Shrestha N, Yousaf M, Ulvic SO, et al. The impact of COVID-19 on globalisation. One Health 2020;11:100180. https://doi.org/10.1016/j.onehlt.2020.100180

24. Baral SD, Rucinski KB, Rwema JOT, et al. The relationship between the global burden of influenza from 2017 - 2019 and COVID-19. JMIR Public Health Surveill 2021;7(3):e24696. https://do org/10.2196/24696

25. Millett GA, Jones A, Benkeser D, et al. Assessing differential impacts of COVID-19 on black communities. Ann Epidemiol 2020;47:37-44. https://doi.org/10.1016/j.annepidem.2020.05.003

26. Department of Health, Eastern Cape. Daily Epidemiological Report for SARS-Cov-2 (Report No. 335) as at 24 March 2021.

27. World Health Organization. International guidelines for certification and classification (coding) of COVID-19 as cause of death. 16 April 2020. https://www.who.int/classifications/icd/Guidelines Cause_of_Death_COVID-19.pdf (accessed on 19 August 2021).

28. Gutierrez JP, Bertozzi SM. Non-communicable diseases and inequalities increase risk of death among COVID-19 patients in Mexico. PLoS ONE 2020;15(10):e0240394. https://doi.org/10.1371/journal. pone. 0240394

29. Omotoso KO, Koch SF. Assessing changes in social determinants of health inequalities in South Africa: A decomposition analysis. Int J Equity Health 2018;17(1):1-13. https://doi.org/10.1186/s12939-018-0885-y

30. Alcendor DJ. Racial disparities-associated COVID-19 mortality among minority populations in the US. J Clin Med 2020;9(8):2442. https://doi.org/10.3390/jcm9082442

31. Suzman R, Beard JR, Boerma T, Chatterji S. Health in an ageing world - what do we know? Lancet 2015;385(9967):484-486. https://doi.org/10.1016/S0140-6736(14)61597-X

32. Mueller AL, McNamara MS, Sinclair DA. Why does COVID-19 disproportionately affect older people? Mueller AL, McNamara MS, Sinclair DA. Why does COVID-19 dispro

33. World Health Organization. World report on ageing and health. 2015. https://www.who.int/ageing/ events/world-report-2015-launch/en/ (accessed 1 April 2021).

34. Mayosi BM, Flisher AJ, Lalloo UG, et al. The burden of non-communicable diseases in South Africa. Lancet 2009;374(9693):934-947. https://doi.org/10.1016/S0140-6736(09)61087-4

35. Phaswana-Mafuya N, Peltzer K, Chirinda W, et al. Self-reported prevalence of chronic noncommunicable diseases and associated factors among older adults in South Africa. Glob Health Action 2013;6:20936. https://doi.org/10.3402/gha.v6i0.20936
36. Kim L, Garg S, O'Halloran A, et al. Risk factors for intensive care unit admission and in-hospital mortality among hospitalised adults identified through the US coronavirus disease 2019 (COVID-19)-associated hospitalisation surveillance network (COVID-NET). Clin Infect Dis 2021;72(9):e206-e214. https://doi. org/10.1093/cid/ciaal012

37. Petrilli CM, Jones SA, Yang J, et al. Factors associated with hospital admission and critical illness among 5279 people with coronavirus disease 2019 in New York City: Prospective cohort study. BMJ 020;369:m1966. https://doi.org/10.1136/bmj.m1966

38. Guan W-J, Ni Z-Y, Hu Y, et al. Clinical characteristics of coronavirus disease 2019 in China. N Engl J Med 2020;382(18):1708-1720. https://doi.org/10.1056/NEJMoa2002032

39. Young M. Private vs. publichealthcare in South Africa. Honours thesis. Kalamazoo, Mich.: Western Michigan University, 2016. https://scholarworks.wmich.edu/cgi/viewcontent.cgi?article=3752\&context=honors _ theses (accessed 23 March 2021)

40. Mayosi BM, Benatar SR. Health and health care in South Africa - 20 years after Mandela. N Engl J Med 2014;371(14):1344-1353. https://doi.org/10.1056/NEJMsr1405012

41. Health e-News. Report: Department of Health Strategic Plan 2014/15 - 2018/9. Department of Health, South Africa, 25 September 2014. https://health-e.org.za/2014/09/25/report-department-healthstrategic-plan-201415-20189/ (accessed 23 March 2021).

42. South African Institute of Race Relations NPC (IRR). Submission to the Department of Health regarding the National Health Insurance Bill of 2018 and the Medical Schemes Amendment Bill of 2018. Johannesburg, 21 September 2018. https://irr.org.za/reports/submissions-on-proposed-legislation/irrfull-submission-nhi-and-msa-bills-21-september-2018-_002 .pdf (accessed 5 April 2021).

full-submission-nhi-and-msa-bills-21-september-2018-_002_pdf (accessed 5 April 2021).
3. Coovadia H, Jewkes R, Barron P, Sanders D, McIntyre D. The health and health system of South Africa: Historical roots of current public health challenges. Lancet 2009;374(9692):817-834. https://doi. org/10.1016/S0140-6736(09)60951-X

44. Centers for Diseases Control and Prevention. Health disparities in health insurance coverage. 2011. https://www.cdc.gov/minorityhealth/chdir/2011/factsheets/Insurance.pdf (accessed 6 April 2021).

45. Statistics South Africa. General household survey 2018. Statistical release P0318. 28 May 2019. http:// www.statssa.gov.za/publications/P0318/P03182018.pdf (accessed 23 March 2021)

46. Nwosu CO, Oyenubi A. Income-related health inequalities associated with the coronavirus pandemic in South Africa: A decomposition analysis. Int J Equity Health 2021;20(1):1-12. https://doi.org/10.1186/ s12939-020-01361-7

47. Mbunge E. Effects of COVID-19 in South African health system and society: An explanatory study. Diabetes Metab Syndr Clin Res Rev 2020;14(6):1809-1814. https://doi.org/10.1016/.dsx.2020.09.016

48. Statistics South Africa. Mortality and causes of death in South Africa: Findings from death notification: 2017. Statistical release P0309.3. 26 March 2020. https://www.statssa.gov.za/publications/P03093/ P030932017.pdf (accessed 23 March 2021).

49. Yancy CW. COVID-19 and African Americans. JAMA 2020;323(19):1891-1892. https://doi.org/10.1001/ jama.2020.6548

50. Tian T, Zhang J, Hu L, et al. Risk factors associated with mortality of COVID-19 in 3125 counties of the United States. Infect Dis Poverty 2021;10(1):1-8. https://doi.org/10.1186/s40249-020-00786-0

51. Louie JK, Acosta M, Winter K, et al. Factors associated with death or hospitalisation due to pandemic 2009 influenza A (H1N1) infection in California. JAMA 2009;302(17):1896-1902. https://doi. org $/ 10.1001 / j a m a .2009 .1583$

52. Dawood FS, Luliano AD, Reed C, et al. Estimated global mortality associated with the first 12 months of 2009 pandemic influenza A H1Nl virus circulation: A modelling study. Lancet Infect Dis 2012;12(9):687695. https://doi.org/10.1016/S1473-3099(12)70121-4

53. Preston SH, Wang H. Sex mortality differences in the United States: The role of cohort smoking patterns. Demography 2006;43(4):631-646. https://doi.org/10.1353/dem.2006.0037

54. West R. Tobacco smoking: Health impact, prevalence, correlates and interventions. Psychol Health 2017;32(8):1018-1036. https://doi.org/10.1080/08870446.2017.1325890

55. Smith LK, Pope C, Botha JL. Patients' help-seeking experiences and delay in cancer presentation: A qualitative synthesis. Lancet 2005;366(9488):825-831. https://doi.org/10.1016/S0140-6736(05)67030-4 56. United Nations. Policy Brief: The impact of COVID-19 on women. 9 April 2020. https://www.un.org/ sexualviolenceinconflict/wp-content/uploads/2020/06/report/policy-brief-the-impact-of-covid-19-onwomen/policy-brief-the-impact-of-covid-19-on-women-en-1.pdf (accessed 23 March 2021)

57. Republic of South Africa: Department of the Presidency. National Development Plan 2030. 2010. https:// www.gov.za/sites/default/files/Executive\%20Summary-NDP\%202030\%20-\%20Our\%20future\%20-\%20 make\%20it\%20work.pdf (accessed 23 March 2021).

Accepted 16 September 2021 